\title{
Cambio de paradigmas en el derecho de familia
}

\author{
Paradigm shift in family law
}

\section{Suevia Sánchez*}

\footnotetext{
* Doctora en Derecho y Ciencias Sociales, Universidad de la República. Exprofesora adjunta de Derecho Privado VI, Facultad de Derecho de la Universidad de la $\mathrm{Re}$ pública. Profesora titular de Derecho de Familia y Sucesiones, Facultad de Derecho de la Universidad CLAEH.

\:sueviasanchez@gmail.com http://orcid.org/0000-00023681-1302
}

RECIBIDO: 14.4 .2020

ACEPTADO: 17.5.2020

\begin{abstract}
Resumen
Los cambios sociales ocurridos en el mundo occidental han transformado la conformación y las relaciones de la familia, y han impactado en el derecho de familia concebido con una visión tradicional, propia del siglo XIX. El trabajo repasa la evolución histórica de la familia y cuáles han sido los cambios sociales y los avances científicos que causaron el deterioro paulatino de los cimientos del derecho de familia, principalmente en dos de sus instituciones fundamentales: el matrimonio y la filiación. Por último, se plantea el estado de situación en Uruguay y la necesidad de reconstruir el derecho de familia sobre nuevas bases que aseguren continuidad, acordes con los requerimientos actuales de la sociedad.
\end{abstract}

Palabras clave: derecho de la familia, familia, matrimonio, Uruguay.

\section{Abstract}

Social changes in western world have determined major transformations in the conformation and the relationships between family members, and have impacted particularly on family law, which was conceived under the traditional vision, typical of the 19th century. This article addresses the historical evolution of family up to the present day, as well as the social changes and scientific advancements that determined the gradual deterioration of family law foundations, mainly in two of. 
its fundamental institutions: marriage and filiation. Finally, the current situation in Uruguay is approached, underscoring the need to rebuild family law on new bases, in accordance with today's social requirements, to guarantee its permanence in time.

Key words: family law, family, marriage, Uruguay.

\section{Parte I. Transformación de la familia y su impacto en el derecho}

\section{Planteamiento: familia y derecho}

Al hablar de familia nos referimos a esa entidad de base natural, de construcción cultural y compleja, en permanente transformación, y de existencia anterior al derecho. Su transformación permanente la destina a cumplir procesos de construcción-deconstrucción-construcción. Dada su complejidad, el análisis de la familia requiere un enfoque multidisciplinario.

En mérito a la interacción que existe entre derecho y realidad social, el derecho se ha encargado de regular la familia a través de múltiples instituciones, como el parentesco, el matrimonio, la filiación, la adopción, la tutela, el régimen de bienes, etc., y lo ha hecho en función de realidades sociales determinadas, de las que extrajo las ideas fuerza que luego transformó en principios inspiradores del sistema normativo establecido en los códigos civiles del siglo XIX.

A partir de entonces, a medida que nuevas realidades sociales lo requerían, el derecho respondió adecuando su normativa, pero manteniendo los mismos principios básicos originales. Esta metodología resultó apropiada mientras esos principios mantuvieron vigencia, a pesar de su paulatino debilitamiento.

Ahora, a partir de las últimas décadas del siglo XX, los cambios sociales y los avances científicos, principalmente en la rama de la biología, adquirieron tal velocidad y magnitud que transformaron la propia configuración sociológica de la familia y, como consecuencia, la concepción social respecto al matrimonio y las relaciones entre los sexos, todo lo cual determinó cambios en la estructura familiar y en sus relaciones internas.

Estas razones son suficientemente valederas para considerar que ya no resulta conveniente continuar el camino de adecuación del derecho sobre las bases tradicionales, las que hasta ahora, si bien habían sufrido impactos importantes, aún mantenían vigencia. 
Compartimos la visión de C. Martínez de Aguirre (2019) en cuanto a que estamos en presencia de un verdadero quiebre en los cimientos del derecho de familia, en especial en dos de sus instituciones más significativas: el matrimonio y la filiación.

\section{Breve reseña histórica de la evolución de la familia en el mundo occidental}

En mérito a la naturaleza de la familia de construcción cultural en permanente transformación, conocer su evolución permite, como lo expresan Bossert y Zannoni (citados por Agencia de los Estados Unidos para el Desarrollo Internacional [USAID] y el Centro de Estudio Ambientales y Sociales [CEAMSO], 2018), comprender el papel que la persona desempeñó en las distintas etapas históricas, revisar ideologías culturales y evaluar con sentido crítico la estructura y el desarrollo que hoy presenta la familia.

A continuación, haremos una breve reseña histórica de la familia, señalando aspectos que la caracterizaron (estructurales y de relación), para luego detenernos con mayor detalle en la época actual (1980 en adelante), cuando deja de existir un modelo único y comienzan a desplegarse múltiples tipos de familia. Así:

- La familia romana estaba constituida por un padre de familia, dueño del hogar, de la esposa, los hijos y sirvientes, quienes le debían obediencia en virtud del poder jurídico que le otorgaba la patria potestad. Durante este período y hasta mediados del siglo XIX, la familia fue la «unidad económica que alberga funciones de reproducción humana y producción material, así como un complejo entramado de relaciones jurídicas» (Halley y Rittich, citado por Observatorio de Conflictividad Civil y Acceso a la Justicia [OCCA], 2019, p. 3).

- La familia patriarcal surgió en la Edad Media, cuando se instituyó el matrimonio como eje central, única vía para la formación de la familia, en el que se depositaron las expectativas y funciones de «los sentimientos amorosos, la sexualidad y la reproducción de la especie, a lo que se agregó la fidelidad como requisito de amalgama para el mantenimiento de dicha triada» (Salinas, 2011, citado por OCCA, 2019, p. 12). En esta época la Iglesia Católica adquirió un rol fundamental en la determinación de los requisitos tanto para formar un matrimonio como para disolverlo. Este modelo patriarcal fue el más generalizado dentro de los grupos dominantes y el único regulado por la ley; no obstante, en el grueso de la población eran frecuentes los nacimientos extramatrimoniales, pese a que la convivencia de parejas sexuales no matrimoniales era entendida como un pecado mortal. Tanto el derecho canónico como el derecho civil se 
caracterizaron por una marcada diferenciación de derechos entre quienes provenían de una familia matrimonial y quienes no.

- La familia nuclear. A mediados del siglo XIX, la modernización del mercado produjo un quiebre en el hogar como sitio de producción material y de alimentos, el cual dejó de ser un espacio semipúblico para transformarse en una «esfera privada, íntima y afectiva» (Halley y Rittich, citado por OCCA, 2019, p. 4). Las características más salientes de la familia de esta época son la monogamia, la heterosexualidad y la normatividad del matrimonio, que determinó una división de roles en función de género: el hombre a cargo de la producción económica en el mercado laboral, proveedor de los recursos, y la mujer dedicada a la reproducción, la crianza y los cuidados de la familia.

- La diversidad familiar. A partir de la década de 1980 se produjo lo que Cheal denominaría el big bang de la teoría de la familia, generado por una ola de críticas internas lideradas por feministas, minorías sexuales, raciales y étnicas (Gallego, 2011). Como aspectos destacables de esta época, se observa: a) la desinstitucionalización de la familia, b) el reconocimiento de múltiples y variadas formas de organización familiar antes rechazadas o ignoradas por el derecho, y c) el desdibujamiento de los límites entre la legitimidad y la ilegitimidad de las familias (Flaquer, 1998).

Los cambios en los comportamientos sociales (disminución de matrimonios, aumento de divorcios, parejas entre personas del mismo sexo y aumento de personas que viven solas) generaron nuevas formas de familia: las ensambladas o reconstituidas, conocidas como «los tuyos, los míos y los nuestros»; las monoparentales, que tienen al frente una sola persona -madre o padre biológico, mujer que decide tener un hijo mediante técnicas de reproducción asistida (en adelante TFHA), padre o madre adoptivos, y familias unipersonales, conformadas en la mayoría de los casos por personas adultas mayores que viven solas.

\section{Principales causas que promovieron transformaciones en la familia}

Las causas principales de los cambios en la esfera familiar son de carácter social, jurídico y científico:

Incursión de la mujer en el mercado laboral y adquisición de nuevos derechos. La revolución industrial marcó un hito en la historia de la humanidad y de la familia en particular: la mujer trascendió del ámbito privado de la familia — donde se 
desenvolvía en forma exclusiva- al ámbito público. Al comienzo, este proceso de incorporación fue promovido por el requerimiento de mano de obra femenina en el mercado de trabajo, y a partir de allí la participación de la mujer se fue extendiendo paulatinamente a otros ámbitos: sociales, sindicales, culturales, científicos y políticos.

Instrumentos internacionales de dignificación de la persona humana, protección de la familia, igualdad de derechos y protección de la infancia. La Declaración Universal de los Derechos Humanos (Naciones Unidas, 1948), marcó el inicio de un proceso de profundización de los derechos humanos, así como el desarrollo de los denominados derechos de la personalidad, tendientes a la dignificación de la persona humana en los diversos ámbitos de la vida, sin distinción de raza, religión ni género.

Trasciende los límites de este trabajo ahondar en el detalle de estos instrumentos internacionales, pero no cabe duda de la importancia que tuvieron en el mundo occidental, principalmente en cuanto a la formación de nuevas concepciones sobre la dignidad y la igualdad de las personas, la promoción de cambios sociales y la generación de importantes efectos en el derecho familiar.

Los avances médicos, en especial de la biología que posibilitaron a las personas:

1. Incidir sobre la procreación, a) para evitarla (métodos anticonceptivos), lo que provocó una marcada disminución de los nacimientos, o b) para lograrla, lo que permitió embarazos hasta entonces imposibles o difíciles de conseguir, recurriendo para ello al propio material genético de la pareja (fertilización homóloga) o al proveniente de donantes externos (fertilización heteróloga). Estas TFHA son de aplicación tanto en parejas heterosexuales como homosexuales de mujeres, y en mujeres solas que desean ser madres.

2. Incidir sobre el género: posibilidad de cambiar de sexo a través de la cirugía y/o tratamientos hormonales.

\section{Análisis de situación del actual derecho de familia}

La dimensión del tema obliga a focalizarnos en dos de las instituciones fundamentales del derecho de familia que recibieron el mayor impacto: el matrimonio y la filiación. Ello no significa que los cambios sociales no hayan tenido fuerte repercusión en otros institutos jurídicos, como la patria potestad, el estado civil de las personas y el parentesco.

Con relación al matrimonio. A lo largo de la historia, el matrimonio fue la institución de mayor significación y arraigo social por su función teleológica relativa a la formación de la familia, la procreación y por ser el ámbito apropiado para el desarrollo 
integral de los hijos. Para el cumplimiento de sus funciones básicas, el matrimonio tenía las siguientes particularidades: a) la unión de dos personas (monogamia), b) de distinto sexo (heterosexualidad), c) de relación intersexual, que derivaba en la procreación, y c) estable (indisoluble), lo que garantizaba la formación de los hijos durante una etapa prolongada.

Las finalidades básicas asignadas al matrimonio, y por tanto las características señaladas, se fueron perdiendo en forma paulatina con el correr del tiempo, principalmente en los siguientes aspectos:

a. Se perdió en buena medida la relación del matrimonio con la procreación. Ello aconteció cuando:

a.1. El matrimonio pasó de ser únicamente una unión heterosexual a permitirse entre personas del mismo sexo (homosexual). Perder la heterosexualidad significó, como expresa Martínez de Aguirre (2019) perder la propia estructura procreativa de la unión.

a.2. Los avances médicos y en particular de la biología hicieron posible el sexo sin procreación (métodos anticonceptivos) y la procreación sin sexo (TFHA), lo que determinó en buena medida la desvinculación entre matrimonio, sexo y procreación.

b. Se perdió la estabilidad del matrimonio. Las leyes de divorcio otorgaron la posibilidad de ruptura del vínculo, cuya máxima expresión la configura el divorcio por sola voluntad, en el que cualquiera de los cónyuges puede poner fin al matrimonio, aun en contra de la voluntad del otro.

Con relación a la filiación. El matrimonio fue concebido con una fuerte relación con la filiación, por cuanto la procreación era una de sus funciones principales y era fruto de la unión intersexual de la pareja, en un marco de fidelidad y vida de consuno. La ley garantizaba el origen biológico de la filiación y para ello articuló un sistema de presunciones absolutas, según las cuales el marido de la madre era considerado padre de la criatura habida por su esposa, presunción que solo era posible destruir a través de alguna de las acciones de Estado reguladas expresamente para dicho fin. Esto ocurría en una época en que la paternidad no era un hecho cierto para la ciencia. En la actualidad este sistema no tiene tanta importancia, por cuanto hoy sí es posible determinar fehacientemente la paternidad mediante un examen de ADN, y por ello el Código de la Niñez y la Adolescencia (CNA) transformó esas presunciones absolutas en relativas.

Actualmente, la importancia de determinar la procedencia biológica del hijo ha disminuido por cuanto la voluntad humana viene ganando terreno. Así:

- Las TFHA permiten acudir a material genético de donantes anónimos de gametos, lo cual desemboca en el establecimiento de filiaciones intencionalmente 
artificiales, basadas exclusivamente en la voluntad de quienes serán los padres jurídicos del hijo que nazca como consecuencia de la aplicación de tales técnicas. En estos casos, la voluntad de ser padres se sitúa por delante de la verdad biológica (Martínez de Aguirre, 2013).

- Por su parte, hoy es posible la adopción conjunta por parejas del mismo sexo, esto es, que se atribuyan vínculos legales simultáneos de paternidad a dos varones o dos mujeres, en caso de utilización de TFHA.

Esto provoca el rompimiento de lo que Martínez de Aguirre (2013) denomina límites de tolerancia de la filiación, al desaparecer el principio de verosimilitud de las filiaciones no biológicas padre-madre-hijo.

El lugar que ha tomado la voluntad de las personas adultas, el derecho a ser padres, ha desvanecido el sistema del Código Civil (CC) fundado en la verdad biológica, además de haber subordinado el interés superior del hijo reconocido por la normativa internacional y plasmado en el CNA.

En suma: se ha producido un distanciamiento gradual en la relación matrimoniofiliación. Como sostiene Martínez de Aguirre (2013):

[...] buena parte de la historia de la evolución del matrimonio en los últimos decenios es la historia de la desvinculación entre matrimonio y procreación (o, lo que es lo mismo, entre matrimonio y filiación); es decir, la historia de cómo el matrimonio tiene cada vez menos que ver con la filiación, y la filiación con el matrimonio (p. 81).

Se observa una desvinculación creciente entre biología y derecho, entre la filiación biológica y aquellas provenientes de la voluntad humana: adopción y progenitura jurídica. Resulta paradójico que hoy, cuando la ciencia puede dar seguridad plena respecto a la paternidad (confirmando la verdad biológica), cobre importancia la voluntad para la determinación de otros tipos de filiación.

En suma: la razón de esta desvinculación es que el matrimonio tal como fue concebido fue perdiendo su naturaleza original. La relación intersexual de la pareja dejó de ser la única forma posible de procreación (TRHA): la ley creó nuevas fuentes de filiación, independientes de la dimensión biológica (adopción y progenitura jurídica). 


\section{Parte II. Evolución del derecho de familia en Uruguay}

\section{Modelo de familia nuclear-tradicional}

En consonancia con la realidad social imperante en el siglo XIX, la familia que reunía mayor prestigio y aceptación social en Uruguay era la conformada por el matrimonio de carácter indisoluble y jerarquizado, con clara diferenciación de roles entre los esposos, producto de la concepción de la superioridad del hombre y la sumisión de la mujer.

Sobre este modelo de familia tradicional y del estado del arte de la ciencia biológica de ese entonces, el CC de 1868 estructuró el derecho de familia como un sistema orgánico y sistemático con el matrimonio como eje central, a partir del cual se regulaban otros institutos, como el estado civil de las personas, el parentesco, la filiación, la patria potestad y el régimen patrimonial.

En cuanto a las relaciones personales entre los esposos, el marido debía protección a la mujer y esta obediencia al marido, quien tenía potestad para decidir en los temas importantes, como la elección del domicilio conyugal o el ejercicio de la patria potestad sobre los hijos menores. La sujeción de la mujer al marido, fruto de prejuicios sociales, fue apuntalada por el derecho, que le disminuyó su capacidad de ejercicio a partir de la celebración del matrimonio; así, como persona incapacitada, requería asistencia de otra persona (el marido).

En cuanto a las relaciones patrimoniales, la mujer, debido a su incapacidad, estaba inhabilitada para administrar bienes, incluso los suyos propios, por lo que el marido era el único administrador de la sociedad conyugal, denominado régimen «de sociedad conyugal y dotal».

\section{Paulatinas transformaciones del modelo patriarcal}

A fin de acompasar las nuevas corrientes, el derecho de familia uruguayo fue incorporando cambios en su normativa, bien a través de leyes específicas que crearon nuevos institutos, bien por modificaciones a otros ya regulados en el CC. La ruptura del modelo patriarcal fue dando paso a otro más abierto y flexible, que el CC original no contemplaba, o del que renegaba.

En la esfera familiar, las transformaciones se dirigieron principalmente a: 
a. la situación de la mujer: divorcio por causal (1907) y por su sola voluntad (1913) e igualación de los derechos civiles de la mujer casada con relación al marido (1946);

b. la situación de los hijos naturales respecto a los provenientes de matrimonio;

c. la apertura a los avances de la biología: adecuación del instituto de la filiación (2004) y regulación de técnicas de reproducción asistida (2013);

d. el reconocimiento jurídico y la regulación del concubinato como opción de familia (2008);

e. la apertura a la libertad sexual: matrimonio entre personas del mismo sexo (2013), y

f. la creación de nuevas fuentes de filiación: adopción (1945) y progenitura jurídica (2013), entre otros.

Como se observa, Uruguay no queda fuera de las consideraciones efectuadas respecto al impacto de los cambios sociales sobre el matrimonio y la filiación.

\section{Consecuencias sociales del distanciamiento entre matrimonio y filiación en Uruguay}

Las razones analizadas precedentemente han producido una desvalorización social de la institución matrimonial. Concomitantemente, la unión libre, que antes no gozaba de aprobación social, se fue convirtiendo en una alternativa válida en la elección de la modalidad de convivencia y de estructura familiar.

De acuerdo al estudio realizado por la Universidad de Montevideo conjuntamente con el diario El País, correspondiente al período 1985-2018, que en parte transcribimos a continuación, en Uruguay se han producido cambios significativos en la esfera de las relaciones de pareja y familia:

1. Disminución de matrimonios y aumento de uniones libres. En 1985 se celebraron 22.792 matrimonios y en 2018 menos de la mitad: 9.518. Por su parte, en 1985 las parejas en unión libre representaban el 4,4\% del total, con lo cual se puede concluir que había 21,7 matrimonios por cada pareja en concubinato. La relación se revirtió y las uniones libres se multiplicaron por cinco en los últimos años. Actualmente la relación entre matrimonios y uniones libres es sensiblemente menor: hay cuatro casados por cada uno que vive en concubinato.

2. Aumento significativo de divorcios. Entre 1985 y 2018 los divorciados crecieron de 4,9\% a 13,1\%, pero, según datos del Registro Civil, la proporción permanece casi incambiada desde los años noventa. Es decir, los matrimonios bajaron a la mitad en 
ese período (3,4 matrimonios por cada divorcio), pero los divorcios también (2,6 en 2018).

3. Nacimiento de nuevos y diversos tipos de familia. Los hogares pasaron de tener 3,4 individuos a 2,8, en promedio. Cada vez son más los niños que viven en hogares monoparentales o reconstituidos y crecen los hogares unipersonales. De la mano de la caída del número de matrimonios — sustituidos en parte por uniones libres-, del incremento de los divorciados o separados y el aumento de la expectativa de vida, desde 1985 hasta hoy ha habido un cambio significativo en las viviendas. Aquel año, el 15\% de los hogares uruguayos eran unipersonales; en el último censo, esa proporción había aumentado más de un 50\% y se ubicaba en 23,4\%, lo que significa casi un cuarto del total de los hogares en 2011 («Revolución dentro hogares», 2019).

Gráfico 1. Distribución de los hogares por tipo de hogar, en porcentaje. Total del país, 2011
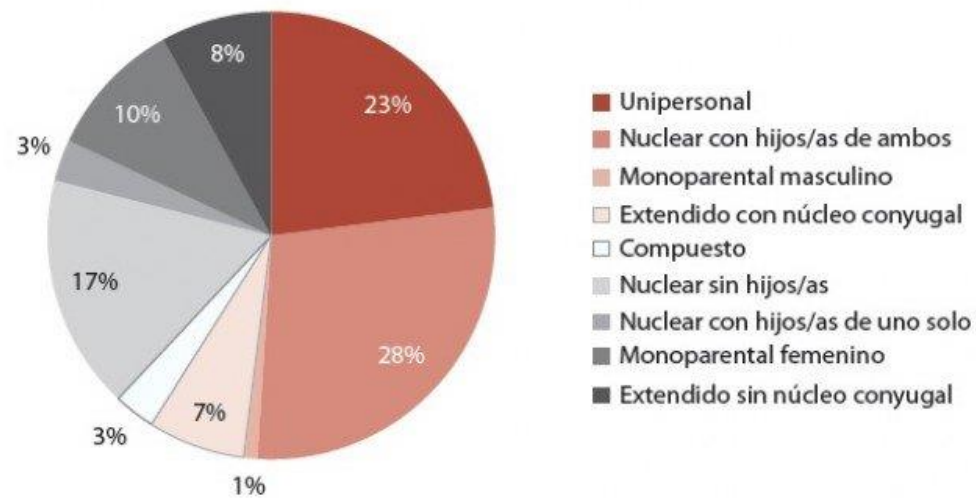

Fuente: «Revolución dentro hogares» (2019).

\section{Parte III. Conclusiones}

No admite discusión el hecho de que el cambio en la consideración social de la familia, así como los avances médicos y biológicos, han debilitado los cimientos del derecho de familia tal como fue concebido por el CC, especialmente en dos de sus instituciones fundamentales: el matrimonio y la filiación. 
En los ciento cuarenta y dos años de vida de nuestro CC, la técnica legislativa empleada para dar respuesta a los requerimientos sociales fue la de introducir modificaciones parciales en diferentes institutos regulados en el CC y aprobar leyes específicas cuando se trataba de crear nuevos institutos del derecho de familia, pero en ambos casos el CC siguió manteniendo aquellas bases que le dieron sustento y que pertenecían a la época de su sanción.

Esta situación ha provocado que el CC haya perdido aquella armonía y sistematización que lo caracterizaron, pues conviven en él instituciones que parten de principios diferentes. Como ejemplos elocuentes basta observar que el matrimonio continúa teniendo un rol fundamental en la formación de la familia, cuando la consideración social respecto de él ha cambiado y la realidad es otra; o bien la confusión que se ha producido en sede de filiación matrimonial cuando se regulan en conjunto dos tipos de filiación que parten de premisas opuestas (filiación biológica, cuya premisa es la verdad biológica, y filiación por progenitura jurídica, que parte del principio inverso, la no verdad biológica).

Ahora el derecho de familia conforma un sistema, integrado por el CC y por el CNA, que se encarga de regular los aspectos jurídicos referidos tanto a la minoridad en general como a la minoridad desamparada y la infractora.

Frente a esta realidad la pregunta es: ¿conviene continuar la misma estrategia de incorporar normativa que responde a diferentes principios o, por el contrario, resulta necesario encarar el cambio jurídico de manera más consistente, actualizando el CC en su conjunto?

Nos inclinamos por la segunda opción, en el entendido de que resulta imperiosa la modificación y actualización del CC. En tal sentido, formulamos las siguientes consideraciones:

1. En cuanto a las estructuras familiares, la nueva regulación debe contener el reconocimiento de la diversidad de estas estructuras, garantizar la igualdad de derechos entre ellas, preservar el equilibrio entre el respeto a la dignidad humana, la libertad individual y la solidaridad entre todos.

No obstante los duros golpes al matrimonio heterosexual, este mantiene vigencia y es uno de los modelos de familia elegidos por un hombre y una mujer para conformar una comunidad de vida, de la que nacen hijos que encuentran un ambiente adecuado para su desarrollo. Si bien la disminución de los matrimonios es importante, esta opción sigue siendo elegida como valedera, con finalidades propias.

En cuanto a la disolución de la familia (cualquiera sea su origen), en mérito a la alta tasa de divorcios y de separaciones, y a la convicción del perjuicio que ello causa a todos los involucrados (hijos, integrantes de la pareja y sociedad), consideramos que debería instrumentarse, como ya existe en varios países (por ejemplo, Estados Unidos), un proceso voluntario a través del cual profesionales imparciales entreguen a las partes 
una opinión confidencial referente al posible resultado del caso, así como un análisis de las fortalezas y debilidades de los argumentos de ambas partes (Leigh, citado por OCCA, 2019). Este sistema considera asuntos como los regímenes de custodia y visitas o las disputas financieras asociadas a la separación, con el objetivo de que las partes cuenten con información útil y recomendaciones de arreglos —-formuladas por profesionalespara tomar decisiones.

2. En cuanto al instituto de la filiación, este debería pasar a ser la base del derecho de familia, por ser el elemento imperecedero por naturaleza. Se requiere establecer los tres tipos de filiación: filiación por naturaleza, filiación adoptiva y filiación por progenitura jurídica, con idénticos efectos, evitando cualquier tipo de discriminación en razón del vínculo filial.

3. Reestructuración de los institutos regulados en función del matrimonio. La nueva regulación debería reestructurar institutos cuya utilidad y vigencia resultan inapelables pero que fueron concebidos en función del matrimonio, como el estado civil de las personas y el parentesco.

4. Cambio de las denominaciones clásicas por otras más actualizadas y no estigmatizantes, a fin de evitar el contenido discriminatorio, así como incorporación de nuevas categorías de relaciones familiares.

\section{En suma}

1. Consideramos imprescindible que Uruguay encare la difícil tarea de actualizar el derecho de familia (libro primero, De las personas, del Código Civil), regulando los institutos que conforman el sistema familia de manera equilibrada en cuanto a las responsabilidades familiares y los derechos de los miembros de la familia, en especial en dos de sus instituciones fundamentales: el matrimonio y la filiación.

2. La tarea de actualización debe acompañarse de la adecuación correspondiente del CNA, en lo que corresponda.

\section{Referencias bibliográficas}

Agencia de los Estados Unidos para el Desarrollo Internacional y Centro de Estudios Ambientales y Sociales (2018). Estudio sobre la asistencia alimenticia y su vinculación con el derecho a la protección de niñas, niños y adolescentes. Recuperado de http://www.ceamso.org.py/upload/publicaciones/1529414129.pdf 
Flaquer, L. (1998). El destino de la familia. Barcelona: Ariel.

Gallego, G. (2011). A propósito de las formas alternas de familia. En H. M. Salinas Hernández (comp.), Políticas públicas, nuevos enfoques y escenarios de la disidencia sexual. Recuperado de https://portalweb.uacm.edu.mx/uacm/Portals/3/1\%20Inicio/video/Hiper\%20Libro\%20Politicas\%20Publicas\%20Nuevos\%20Enfoques/Pol\%C2\%A1ticas\%20p\%C2\%A3blicas,\%20nuevos\%20enfoques $\% 20 \mathrm{y} \% 20$ escenarios\%20de\%20la\%20disidencia\%20sexual.pdf

Martínez de Aguirre, C. (2013). La filiación, entre la biología y el derecho. Prudentia Iuris, 76, 117-133.

Martínez de Aguirre, C. (2019). El derecho de familia en el mundo occidental: Perspectiva y prospectiva. Ius Familiae, 31(1), 117-134.

Naciones Unidas (1948). Declaración universal de los derechos humanos. Recuperado de https://undocs.org/es/A/RES/67/97

Observatorio de Conflictividad Civil y Acceso a la Justicia. (2019). Conflictividad civil y barreras de acceso a la justicia en América Latina: Informe de relaciones de pareja y familias. Santiago de Chile: OCCA.

La revolución dentro de los hogares: ¿cómo cambiaron las familias uruguayas? (24 de diciembre, 2019). El País, Suplemento Semanal. Recuperado de https://www.elpais.com.uy/que-pasa/revolucion-hogares-cambiaron-familias-uruguayas.html. 